\title{
Mesenchymal stem cell infusion for the treatment of neurological sequelae of canine distemper virus: a clinical study
}

\author{
D.S.V. Gonçalves ${ }^{1}$, M.V.S. Gomes ${ }^{1}$, V.L.P. Guterra ${ }^{1}$, \\ A.F. Lucchi-Rodrigues ${ }^{1}$, C.H.T. Mathias ${ }^{1}$, L.F.P. Maestri ${ }^{2}$, \\ N.M. Argôlo-Neto ${ }^{3}$ and B.S. Monteiro ${ }^{1}$ \\ ${ }^{1}$ Laboratório de Células Tronco e Terapia Celular, Programa de Pós-Graduação \\ em Ciência Animal, Universidade de Vila Velha (UVV), Vila Velha, ES, Brasil \\ ${ }^{2}$ Faculdade de Medicina Veterinária, Universidade de Vila Velha, ES, Brasil. \\ ${ }^{3}$ Núcleo Integrado de Morfologia e Pesquisas com Células-Tronco, \\ Universidade Federal do Piauí, Teresina, PI, Brasil.
}

Corresponding author: D.S.V. Gonçalves

E-mail: darieleg@hotmail.com

Genet. Mol. Res. 17 (4): gmr18088

Received July 26, 2018

Accepted October 02, 2018

Published October 09, 2018

DOI http://dx.doi.org/10.4238/gmr18088

\begin{abstract}
We investigated the effects of an allogenic infusion of mesenchymal stem cells derived from adipose tissue for treatment of dogs with neurological sequelae secondary to infection with canine distemper virus. Seven dogs were selected, all of which presented positive PCR for canine distemper and later, after clinical treatment, presented negative PCR but retained at least one post-infection neurological signal. Cell therapy was performed on days 1,15 , and 30; blood samples were taken on days 1 and 30for a hemogram, and the animals were evaluated on days $1,15,30,45$, and 180 for walking characteristics, urinary or fecal incontinence, state of consciousness, myoclonus, and occurrence of seizures. A descriptive numerical scale was established for scoring and classifying the various parameters that were evaluated. All the animals demonstrated post-therapy clinical neurological improvement, especially for the parameters walking and urinary and fecal incontinence; this improvement was significant throughout the evaluation period. Allogenic infusion of mesenchymal stem cells derived from adipose
\end{abstract}


tissue in dogs with neurological sequelae secondary to infection by the canine distemper virus proved to be an efficient treatment.

Key words: cell signaling; cell therapy; immunomodulation; contagious infectious diseases.

\section{INTRODUCTION}

Canine distemper is an infectious multisystem disease caused by the canine distemper virus. Following infection and contact with the epithelium of the upper respiratory tract, the virus multiplies in tissue macrophages and circulating $\mathrm{T}$ and $\mathrm{B}$ cells, spreading to the tonsils and the bronchial lymph nodes (Beineken et al., 2009; Greene and Vandevelde, 2012), initiating replication in the lymphoid tissue (Martella et al., 2008). Viral replication leads to severe and long-lasting immunosuppression (Carvalho et al., 2012), spreading to the lymphatic ganglia (Takenaka et al., 2016), through the blood (Beineken et al., 2008), and viral particles are disseminated throughout the body (Takenaka et al., 2016),with an incubation period of between 1 and 4 weeks (Martella et al., 2008; Beineken et al., 2015).

The clinical signs manifested by the patient, and their recovery, depend on the immune response of the host. A strong immune response (suppressor) can eliminate the virus before it multiplies in the host cells and can minimize clinical changes and achieve complete recovery of the animal (Martella et al., 2008), while a weak or delayed response can lead to virus propagation (Beineken et al., 2015), reaching the epithelial tissues and the central nervous system (CNS) and causing several clinical signs, including neurological sequelae (Beineken et al., 2009; Greene and Vandevelde, 2012) which, depending on their intensity, can be fatal (Beineken et al., 2009).

Between 40 and 50 days after infection, during what is considered the chronic phase, neurological signs are a consequence of demyelination (Martella et al., 2008). In this process, cytotoxic CD8 $+\mathrm{T}$ cells activated by proinflammatory cytokines, such as interleukin-6, IL-8, tumor necrosis factor, and interleukin-12 (Beineken et al., 2009; Seehusen et al., 2016), infiltrate the myelin sheath, causing its destruction, resulting inimpaired nerve signal conduction, movements, cognition, and other functions, depending on the region involved, which may provoke paresis, paralysis, myoclonus, fasciculation, involuntary jaw movement, and convulsions in these patients.

Due to the high morbidity and mortality rates associated with distemper, alternatives are sought to minimize symptoms and the sequelae in infected patients. In this search for therapies, treatment with mesenchymal stem cells (MSC) has emerged as a promising option. MSCs are a lineage of somatic stem cells present in small quantities in the perivascular regions of all adult tissues; they have the capacity to differentiate into other cells and/or produce signaling molecules (growth factors) in the organism, increasing tissue repair processes (Meirelles et al., 2008; Pinto Filho et al., 2013).

Advances in stem cell research have been driving therapies for the treatment of various conditions in veterinary medicine. Although there has been much speculation about the benefits of stem cell therapy canine distemper, and some clinical therapies have been publicized on social networks, few scientific articles have been published. Recently, summaries of several unpublished scientific events and/or studies of interactions between 
bone marrow cell fractions and stem cells and distemper have appeared, but with few publications in research periodicals involving clinical studies of dogs with canine distemper, such as that of Pinheiro et al. (2016), who treated dogs in the acute phase of the disease with $\underline{\text { MSC, }}$ or that by Monteiro (2017).

The lack of technical-scientific references regarding the advantages and disadvantages of MSC therapy for the treatment of distemper, and the large number of dogs with sequelae secondary to the infection that compromise quality of life $\mathrm{w}$ prompted the development of this study.

\section{MATERIAL AND METHODS}

\section{Animal selection and study inclusion criteria}

Seven dogs were selected from the small animal clinic of the Veterinary Hospital of the University Vila Velha. For inclusion in the study, these patients had to present a positive PCR for Canine Distemper Virus and, subsequently, following clinical treatment, present a negative PCR but retain at least one neurological sign characterized as a sequel of the distemper. These animals came from a prior study in which the occurrence of 12 contagious infectious diseases in canines was investigated.

When an animal was considered suitable to participate in the research, the owner was contacted, informed about the cell therapy study, and invited to authorize the inclusion of their dog in the project by signing a consent form. The clinical assessments and cell therapy were conducted from September to October 2017 and follow-up of the results lasted until March 2018, for a total of 180 days of evaluation.

The study involving cell therapy was submitted to the University Vila Velha Animal Ethics Committee, approved, and registered under number 2952013.

\section{Patient evaluation criteria and evaluation times}

A clinical record sheet was completed for the selected study animals, which included the patient's medical history, = a clinical exam and laboratory test data. The evaluation times were established at day 1 (the first cell therapy), day 15 (second cell therapy), day 30 (third cell therapy), day 45 (15 days after the third cell therapy), and day 180 (the end of the observation period).

During the medical case history interview, questions were asked about gastrointestinal disturbances such as anorexia, dysphagia, vomiting, diarrhea, constipation, convulsions, the use of medications, and the attitude/behavior of the patient at home. During clinical evaluation, temperature, heart rate, respiratory rate, the coloration of the mucous membranes, capillary refill time, and weight were observed. The neurological examination consisted of looking for any relevant changes, mainly an inability to stay still, difficulty in walking, myoclonus, hyperreflexia, involuntary chewing movements, urinary and fecal incontinence, and the state of consciousness during the evaluation. Some of these changes were filmed during the examination, for quantification in minutes of myoclonus and mandibular myoclonus, for example. When seizures were reported, their frequency and duration were noted for future comparisons. 
Blood tests were performed during the study. The blood samples were collected by venipuncture of the cephalic or jugular veins prior to the first cell therapy and 15 days after the second therapy. Total cell counts were measured using hematology equipment and a differential leukocyte count was obtained from blood smears.

For the purpose of characterizing the evolution of the patients during the evolution period, classification scores were established for each of the variables walking, urinary and fecal incontinence, state of consciousness, seizures, and myoclonus, based on the initial observation conducted on day 1 , determining the creation of a descriptive numerical scale, called the Gonçalves-Monteiro system (Table 1).

Table 1 - Descriptive numerical scale for the assessment of the variables walking, urinary and fecal incontinence, state of consciousness, seizures, and myoclonus presented by patients with neurological sequelae secondary to infection by the canine distemper virus and treated with mesenchymal stem cells, called the Gonçalves-Monteiro system.

\begin{tabular}{|c|c|c|}
\hline Characteristics evaluated & Description & Score \\
\hline \multirow{5}{*}{ Walking } & $\begin{array}{l}\text { Animal lies on its side, does not tolerate handling, is not capable of changing position, and presents } \\
\text { rigidity in leg and neck muscles. }\end{array}$ & 0 \\
\hline & $\begin{array}{l}\text { Animal lieson its side, with tetraparesis, but is capable of dragging itself, changing position, and } \\
\text { assuming a sternal decubitus position. When encouraged to walk, demonstrates imbalance and falls. }\end{array}$ & 1 \\
\hline & Animal walks with ataxia and imbalance that can result in falls. & 2 \\
\hline & Animal walks with mild ataxia & 3 \\
\hline & Animal walks normally, without ataxia or imbalance. & 4 \\
\hline \multirow{3}{*}{ Urinary and fecal incontinence } & Animal is totally incontinent or with urinary and fecal retention. & 0 \\
\hline & Animal is partially incontinent. & 1 \\
\hline & Animal is not incontinent, with total urinary and fecal control. & 2 \\
\hline \multirow{3}{*}{ State of consciousness } & Animal is apathetic, non-responsive to environmental stimuli. & 0 \\
\hline & Animal is apathetic, but responsive to environmental stimuli. & 1 \\
\hline & Animal is alert. & 2 \\
\hline \multirow{4}{*}{ Seizures } & Animal has frequent and long-lasting seizures, not controlled with medications. & 0 \\
\hline & Animal has frequent seizures, but controlled with medications. & 1 \\
\hline & Animal has sporadic seizures, but controlled by medications. & 2 \\
\hline & Animal does not have seizures. & 3 \\
\hline \multirow{5}{*}{ Myoclonus/ Fasciculation } & $\begin{array}{l}\text { Animal has marked generalized myoclonus/fasciculation in the head, neck, thoracic and pelvic limbs, } \\
\text { with or without involuntary chewing movements. }\end{array}$ & 0 \\
\hline & $\begin{array}{l}\text { Animal has marked myoclonus/fasciculation only in the head and neck region or only in the thoracic } \\
\text { and pelvic limbs, accompanied by involuntary chewing movements. }\end{array}$ & 1 \\
\hline & $\begin{array}{l}\text { Animal has marked myoclonus/fasciculation only in the head and neck region or only in the thoracic } \\
\text { and pelvic limbs, without involuntary chewing movements. }\end{array}$ & 2 \\
\hline & Animal has mild myoclonus/fasciculation with or without involuntary chewing movements. & 3 \\
\hline & Animal does not have myoclonus/fasciculation or involuntary chewing movements. & 4 \\
\hline Summary of scores & & 15 \\
\hline
\end{tabular}

For a general evaluation of the patient during the 180 days, the scores of the five variables were summed up within each observation time, ranging from 0 to 15 . For each patient, the difference obtained between the scores the first and last evaluation day was counted, allowing the calculation of a coefficient of variation. It was determined that the higher values obtained from this coefficient would represent the best clinical evolution among treated animals. 


\section{Cell Therapy}

All the animals underwent three allogenic MSC infusions, at a dose of $5.0 \times 10^{6}$ cells/3.0 mL of PBS (phosphate buffered saline), intravenously, on days 1,15 , and 30 of the study. The MSCs used during the study were processed in the UVV Stem Cell and Animal Therapy Laboratory(LCET) in accordance with pre-established protocols for the laboratory routine (Monteiro et al., 2015; Oliveira et al., 2017). After each treatment, the owners were instructed to contact the researchers if they observed any behavioral or clinical changes in the patients. No dietary, physical, or drug restrictions were imposed on the patients.

Fragments of adipose tissue of approximately $1.0 \mathrm{~cm}^{3}$ (equivalent to 1 gram) were collected aseptically from the abdominal regions of three young female dogs that underwent selective ovariohysterectomy at the Veterinary Hospital. The adipose tissue samples were stored in Falcon 50 tubes containing 20mL of complete DMEM (Dulbecco's Modified Eagle's Medium - culture medium plus antibiotic, antifungal, and bovine fetal serum) at room temperature. In the laboratory, under a laminar flow hood, the growth medium was removed from the tube and the adipose tissue samples were washed with phosphate buffered saline (PBS) to remove traces of blood and cellular debris. The adipose tissue was fragmented into small pieces and transferred to a second tube containing $20 \mathrm{~mL}$ of collagenase type I solution and incubated at $37^{\circ} \mathrm{C}$ and $5 \% \mathrm{CO}_{2}$ for 45 minutes.

After 45 minutes, the tube was removed from the incubator and centrifuged for 10 minutes at 2000rpm. The supernatant was discarded and the cellular pellet formed was resuspended in $10 \mathrm{~mL}$ of PBS. The tube was centrifuged again, the supernatant discarded, and the cellular pellet resuspended in $15 \mathrm{~mL}$ of complete DMEM. Three milliliters $(3 \mathrm{~mL})$ of the cellular solution was transferred to a $75 \mathrm{~cm}^{2}$ culture flask and $15 \mathrm{~mL}$ of complete DMEM was added per flask, which were incubated at $37^{\circ} \mathrm{C}$ and $5 \% \mathrm{CO}_{2}$. The cultures were observed daily and when they reached $80 \%$ confluence, trypsinization and cell subculturing steps were performed. Cells from the fourth passage were used for difference characterization steps, such as flow cytometry and in vitro osteogenic differentiation, and/or used for cell therapy. On the day of cell application in the patients, the doses used for each application were prepared, quantified, distributed into seven syringes of $3.0 \mathrm{~mL}$, one for each patient, and stored in a chilled styrofoam cooler with ice pads in it until application time.

\section{Statistical Analysis}

Data tabulation and statistical evaluation were conducted with the assistance of Graphpad Prism ${ }^{\circledR}$ software. All the values obtained were submitted to a KolmogorovSmirnov test to test for normality of distribution. For the non-parametric variables classified as scores, independent evaluations were made over time using the Friedman test followed by a Dunn post-hoc test, adopting a level of null hypothesis rejection of $5 \%(\mathrm{p} \leq 0.05)$.

For the general assessment of the patient we used descriptive analysis, considering a scale of 0 to 15 , and a coefficient of variation. These values, when greater than or equal to $(\geq)$, indicate that cell therapy led to an improvement in the patient. 


\section{RESULTS}

The cells derived from the adipose tissue met all the requirements for adhesion to a plastic substrate, differentiation in culture medium, and membrane receptor expression profile consistent with a population of mesenchymal stem cells, starting from the fourth passage. The mean concentration of application doses was $5.0 \times 10^{6}$ cells $/ 3.0 \mathrm{~mL}$ of PBS.

Of the seven patients included in the study, six were males and one was a female, with a modalage of 5 years, body weight between 1.9 and $23.0 \mathrm{~kg}$, and of different races, including non-defined breed. The body temperature, pink colored mucous membranes, capillary refill time, heart and respiratory rates, percentage hydration, hematocrit, and leukocyte count were within the normal ranges for the species for all the patients at all evaluation times. There were no complaints of anorexia, vomiting, or diarrhea. The main characteristics of the patients are presented in Table 2; the patients were allocated to the study using the nomenclature of A to G.

Table 2 - List of the seven patients used in the study presenting age, breed, and weight (NDB = non-defined breed).

\begin{tabular}{lccc}
\hline \multirow{2}{*}{ Animals } & \multicolumn{3}{c}{ Patient characteristics } \\
\cline { 2 - 4 } & Age (years) & Breed & Weight (Kg) \\
\hline$A$ & 5 & NDB & 12.8 \\
$B$ & 5 & NDB & 10.3 \\
$C$ & 6 & Pinscher & 3.8 \\
$D$ & 5 & NDB & 23.0 \\
$E$ & 1.5 & NDB & 14.4 \\
$F$ & 7 & Poodle & 5.9 \\
$G$ & 6 & Pinscher & 1.9 \\
\hline
\end{tabular}

During the first evaluation, we noted that six patients had difficulty walking, especially patients $\mathrm{A}, \mathrm{C}$, and $\mathrm{G}$, which remained only lying on their side, rigid, and could not tolerate sternal decubitus, and patient $\mathrm{E}$, which tolerated sternal decubitus and was able to drag itself along, but with paraparesis of the pelvic limbs. The complaint of urinary incontinence was common to five patients and patients $\mathrm{A}, \mathrm{C}, \mathrm{E}$, and $\mathrm{F}$ began to have seizures following infection from the distemper virus and had to use phenobarbital continuously.

At this first contact, three patients were apathetic, although of these patient A began to present hyperreflexia and agitation in response to touch and sound stimuli, and the other four patients presented a normal level of consciousness. Patients $\mathrm{A}$ and $\mathrm{C}$ only ate with the help of their owners, who had to force feed them with pureed foods and patients C, F, and G had dysphagia. Throughout the study, the serology of patient A was reactive for toxoplasmosis, however, it was not excluded from the research.

In the evaluation of patient $\mathrm{A}$ on day 1 , the dog was lying on its side, with tetraparesis; it did not try to change position and presented urinary and fecal incontinence, hyperreflexia in response to touch and noise, leading to agitation alternating with a state of apathy. It had tonic-clonic seizures with relaxation of the urinary and fecal sphincters and epilepsy that was not controlled with medication (phenobarbital). When at rest, it had myoclonus in the cervical region (113 movements/minute). At 15 days, it also remained lying on its side, with tetraparesis and without being able to drag itself; however, it began to change its position alone. The patient was more alert than at the first evaluation and continued with hyperreflexia in response to touch and noise. There was no change in 
relation to seizures. The myoclonus wass lightly reduced (100 movement/minute) and the owner reported that the animal was hungrier and thirstier, but still needed help eating. At 30 days, the patient began to lie in sternal decubitus to eat, was more alert, but continued to have seizures, though their duration and frequency had decreased. At 45 days, the owner continued to notice evolution in the patient's state of alertness, increased appetite, ability to stay in sternal decubitus for longer periods of time, and that there were no longer any signs of incontinence during seizures. At 180 days, the owner reported that the patient had rare episodes of convulsion, was eating by itself, and was trying to walk, yet without success.

Patient $\mathrm{B}$, on day 1 , presented ataxia and paraparesis in the pelvic limbs when walking, sometimes falling as a result, had urinary and fecal incontinence, was alert, and had no history of either seizures or myoclonus. At 15 days, there was an improvement in ataxia during walking, but the urinary and fecal incontinence persisted. At 30 days, the ataxia was very mild, there was neither paraparesis of the pelvic limbs nor loss of balance when turning, and the owner reported fewer episodes of incontinence. At 45 and 180 days, the clinical signs were similar, however, the owner confirmed that the animal now had control of both its bladder and bowels.

On day 1, Patient Conly lied on its side and exhibited tetraparesis, hyperextension of all limbs, and rigidity of the neck. When positioned in sternal decubitus, it demonstrated anxiety and pain. It was able to manage urinary and fecal retention, but needed its owner's intervention. It was apathetic, without any interaction with the environment and had weekly seizures controlled with medication (phenobarbital). We noted similarities in the 15- and 30-day evaluations, in which the patient still stayed lying on its side, although when positioned in sternal decubitus it was able to tolerate this position and the neck muscles were less rigid. It still presented tetraparesis and the owner was performing small movements of flexion and extension of the thoracic and pelvic limbs. At 45 days, we noted evolution of voluntary movements of the head, the animal stayed in sternal decubitus, appeared to be more alert and responsive to the manipulations, and since no seizures were observed, the owner was instructed to increase the intervals of the medication. Other developments reported by the owner were an increase in appetite and voluntary food intake by the dog, in addition to being able to urinate spontaneously without a need for bladder compression, but without total control. At 180 days, the patient presented urinary and fecal control and there were no reports of seizures, but the owner continued to administer the medications every 48 hours. Based on the postural evolution of the patient, weekly physical therapy sessions were initiated.

Patient D, on day 1, walked with mild ataxia, presented myoclonus of the jaw (112/movements/minute) and excessive salivation, and the owner complained that the patient could not lift its tail. It had urinary and fecal incontinence, with dermatitis in the abdominal and perineal regions. It was alert and had no history of convulsions. When at rest, it exhibited myoclonus of the pelvic (128 movements/minute) and thoracic (100 movements/minute) limbs and in the neck. There was a discreet improvement during treatment and evaluations. Starting at day 30, the salivation decreased despite the persistence of mandibular myoclonus. The animal was able to lift its tail sporadically, had better urinary control, and had no more dermatitis in the abdominal and perineal regions, in addition to an increase in appetite reported by the owner. At 180 days, the myoclonus of the pelvic (108 movements/minute) and thoracic (96 movements/minute) limbs had decreased slightly. The mandibular myoclonus had decreased to 76 movements per minute. 
On day 1, Patient $\mathrm{E}$ was alert and lying on its side, with tetraparesis, but could drag itself and change position. It tried to walk placing its weight on the thoracic limbs, but lost its balance and fell. It presented urinary and fecal incontinence. It had several seizures during the day, even with medication. Myoclonus occurred in the left pelvic limb (132 movements/minute) and the right thoracic limb (132 movements/minute). At 15 days, it continued lying on its side, with tetraparesis, dragging itself and changing position. The owner reported that the patient had urinary control and was not urinating any longer in the place where it slept and that its appetite was improving. At 45 days, the patient made more attempts to walk, still shifting weight to the thoracic limbs, but succeeded in making some headway before losing balance and falling. At 180 days, the animal was walking better, although still with ataxia and imbalance. The seizures had not recurred for two months, but the owner continued to give the medication at 48 hour intervals. The animal maintained urinary control and had a better appetite. Myoclonus of the left pelvic limb had decreased (100 movements/minute).

Patient $\mathrm{F}$ was alert on day 1, walked normally, but had been mutilating its distal phalanges and pads, which remained bandaged. It had no history of urinary or fecal incontinence or myoclonus. It had seizures, which were under control with medication (phenobarbital). At 15 and 30 days, it continued to walk normally with less mutilation of its distal phalanges and pads, in fact, the protective bandages were only needed on one of the limbs, the right pelvic limb. The animal was on medication and no seizures were reported during this interval. At 45 days, the only change reported was an increase in the interval of the anticonvulsant medication, without the manifestation of seizures. At 180 days, the interval of the anticonvulsant was increased to 24 hours without the occurrence of new seizures, but the patient returned to interfering with the extremities of its limbs.

Patient $\mathrm{G}$ showed the most clinical evolution of the parameters that were evaluated. On day 1 , the patient was apathetic and lying on its side, with tetraparesis, though able to drag itself and change position. When positioned in sternal decubitus, it was imbalanced and uncomfortable with movements of the head ( 80 movements/minute). It had urinary incontinence and had no history of convulsions. Myoclonus was evident in the lips and neck (104 movements/minute). At 15 days, it walked ataxically and no longer remained only lying on its side. The owner reported that the patient was more active, responsive to environmental stimuli, and even barked when upset. At 30 days, the patient walked better, was able to go up and down the stairs, and myoclonus of the lips and movements of the head had diminished (56 movements/minute and 60 movements/minute, respectively). The patient was no longer incontinent and displayed territory marking behavior. During cell therapy application, the animal had to be contained with a muzzle and by the owner in order to be able to insert the needle into its vein. At 45 days, the owner mentioned that the patient stayed in the window of the house and barked at children passing in the street on their way to school. At 180 days, it was very active, with only slight movements of the mouth and mild ataxia when walking, and was escaping from the house to run in the street.

The evaluations of the main clinical changes demonstrated by the patients are presented in Table 4. Only the variables walking and urinary and fecal incontinence differed significantly, comparing time 180 with time 0 , with values of $p=0.0019$ and $p=0.0006$, respectively, even though clinical evolution was examined for all the variables.

The sum of the score values of the variables observed showed a pattern of evolution over time, reinforcing the presumption of a positive contribution from therapy in the 
animals and the evolution of its effects over time. Using the coefficient of variation values, we infer that the patient that most benefited from the therapy was the animal classified as G, followed, sequentially, by A, C, E, D, B, and F.

Table 4 - Evaluations during the 180-day evaluation period, according to the proposed descriptive numerical scale, of the main clinical changes of the patients that presented neurological sequelae secondary to infection by canine distemper virus and were treated with mesenchymal stem cells.

\begin{tabular}{|c|c|c|c|c|c|c|c|c|}
\hline \multirow[b]{2}{*}{ Patient } & \multicolumn{5}{|c|}{ VARIABLES } & \multirow{2}{*}{$\begin{array}{l}\text { Time of } \\
\text { evaluation } \\
\text { (days) }\end{array}$} & \multirow{2}{*}{$\begin{array}{l}\text { Summary of } \\
\text { the scores for } \\
\text { all variables }\end{array}$} & \multirow{2}{*}{$\begin{array}{c}\text { Interval of evolution } \\
\text { (Coefficient of } \\
\text { Variation) }\end{array}$} \\
\hline & Walking & $\begin{array}{l}\text { Urinary and fecal } \\
\text { incontinence }\end{array}$ & $\begin{array}{c}\text { State of } \\
\text { consciousness }\end{array}$ & Seizures & $\begin{array}{l}\text { Myoclonus/ } \\
\text { Fasciculation }\end{array}$ & & & \\
\hline \multirow{5}{*}{ A } & 0 & 1 & 1 & 0 & 2 & 1 & 4 & \multirow{5}{*}{$\begin{array}{c}5 / 15 \\
(0.314)\end{array}$} \\
\hline & 1 & 1 & 1 & 0 & 2 & 15 & 5 & \\
\hline & 1 & 1 & 2 & 1 & 2 & 30 & 7 & \\
\hline & 1 & 2 & 2 & 1 & 2 & 45 & 8 & \\
\hline & 1 & 2 & 2 & 2 & 2 & 180 & 9 & \\
\hline \multirow{5}{*}{ B } & 2 & 0 & 2 & 3 & 4 & 1 & 11 & \multirow{5}{*}{$\begin{array}{c}3 / 15 \\
(0.102)\end{array}$} \\
\hline & 3 & 0 & 2 & 3 & 4 & 15 & 12 & \\
\hline & 3 & 1 & 2 & 3 & 4 & 30 & 13 & \\
\hline & 3 & 2 & 2 & 3 & 4 & 45 & 14 & \\
\hline & 3 & 2 & 2 & 3 & 4 & 180 & 14 & \\
\hline \multirow{5}{*}{$\mathrm{C}$} & 0 & 0 & 0 & 1 & 4 & 1 & 5 & \multirow{5}{*}{$\begin{array}{c}6 / 15 \\
(0.287)\end{array}$} \\
\hline & 1 & 0 & 1 & 1 & 4 & 15 & 7 & \\
\hline & 1 & 1 & 1 & 2 & 4 & 30 & 9 & \\
\hline & 1 & 1 & 2 & 2 & 4 & 45 & 10 & \\
\hline & 1 & 2 & 2 & 2 & 4 & 180 & 11 & \\
\hline \multirow{5}{*}{ D } & 3 & 0 & 2 & 3 & 0 & 1 & 8 & \multirow{5}{*}{$\begin{array}{c}4 / 15 \\
(0.183)\end{array}$} \\
\hline & 3 & 0 & 2 & 3 & 0 & 15 & 8 & \\
\hline & 3 & 1 & 2 & 3 & 1 & 30 & 10 & \\
\hline & 4 & 1 & 2 & 3 & 1 & 45 & 11 & \\
\hline & 4 & 2 & 2 & 3 & 1 & 180 & 12 & \\
\hline \multirow{5}{*}{ E } & 1 & 0 & 2 & 0 & 2 & 1 & 5 & \multirow{5}{*}{$\begin{array}{c}6 / 15 \\
(0.261)\end{array}$} \\
\hline & 1 & 2 & 2 & 1 & 2 & 15 & 8 & \\
\hline & 1 & 2 & 2 & 1 & 3 & 30 & 9 & \\
\hline & 1 & 2 & 2 & 1 & 3 & 45 & 9 & \\
\hline & 2 & 2 & 2 & 2 & 3 & 180 & 11 & \\
\hline \multirow{5}{*}{$\mathrm{F}$} & 4 & 2 & 2 & 1 & 4 & 1 & 13 & \multirow{5}{*}{$\begin{array}{c}1 / 15 \\
(0.040)\end{array}$} \\
\hline & 4 & 2 & 2 & 1 & 4 & 15 & 13 & \\
\hline & 4 & 2 & 2 & 2 & 4 & 30 & 14 & \\
\hline & 4 & 2 & 2 & 2 & 4 & 45 & 14 & \\
\hline & 4 & 2 & 2 & 2 & 4 & 180 & 14 & \\
\hline \multirow{5}{*}{ G } & 0 & 0 & 1 & 3 & 0 & 1 & 4 & \multirow{5}{*}{$\begin{array}{c}9 / 15 \\
(0.363)\end{array}$} \\
\hline & 2 & 1 & 2 & 3 & 2 & 15 & 10 & \\
\hline & 2 & 2 & 2 & 3 & 2 & 30 & 11 & \\
\hline & 3 & 2 & 2 & 3 & 3 & 45 & 13 & \\
\hline & 3 & 2 & 2 & 3 & 3 & 180 & 13 & \\
\hline
\end{tabular}

\section{DISCUSSION}

Mesenchymal stem cellsplay an important role in tissue protection, releasing growth factors, signaling molecules, and cytokines, especially when these tissue receptors are being injured (Uccelli et al., 2011), and according to Abreu-Júnior et al. (2014), even secreting neurotrophic factors that favor neurogenesis, angiogenesis, and contribute to synapses and the remyelination of injured axons. These characteristics associated with this cell type are the reason behind their wide use in preclinical and clinical studies as a therapeutic strategy (Moazzami et al., 2014; Kanamaru et al., 2015) and our conducting this investigation to evaluate the clinical effects of MSC therapy on neurological changes developed by dogs affected by canine distemper virus. 
When intravenous therapy was chosen, according to the proposed methodology, the ease of access to the vein for the cell transplant and the broad distribution that the blood stream can provide in the diffusion of cells and their molecules were taken into consideration (Fischer et al., 2009). However, these authors demonstrated that a large number of infused cells became established in the pulmonary alveoli due to the size of the cells and/or adhesion to the receptors, demonstrating that effective stem cell therapy requires a minimum number of $2.0 \times 10^{6}$ cells, justifying the choice of a dose of $5.0 \times 10^{6}$ cells/3.0 mL of PBS in the MSC infusions administered during our study.

The condition caused by the canine distemper virus includes a series of respiratory and gastrointestinal signs (Beineken et al., 2015), especially in the acute phase. When they affect the central nervous system, they cause a variety of manifestations resulting from damage to the transmission of nerve signals, altering movement, cognition, and other functions that rely on the affected nerves (Beineken et al., 2009; Greene and Vandevelde, 2012).As a result of the various neurological modifications, we observed several changes in the patients, considered to be sequelae from the viral infection, which were manifested with varying intensities, among them paresis, paralysis, myoclonus, fasciculation, involuntary chewing movements, and seizures, which generated a need for a descriptive numerical scale to standardize patient assessment.

We found that at 15 days following the first cell therapy application, the animals began to present a slight decrease in the sequelae; after 30 days of therapy, there was noticeable improvement and the clinical evolution associated with the minimization of the signs was maintained throughout the observation period. These benefits continued to increase after the third infusion. Marques (2016), who also treated dogs with distemper, used two or three MSC infusions in patients and observed that with only two applications recovery of the patients was not achieved. Corroborating what was found by the abovementioned author, we concluded that using three doses is the minimum protocol for treatment against sequelae from distemper.

Also, regarding the proposed descriptive numerical scale, we considered using the evaluation system with scores proposed by Olby et al. (2001); however, those authors generated their classification system to evaluate functional evolution and recovery only in dogs with spinal cord injuries. Significant adaptations to the Olby system would be required for application to patients with distemper and so the idea of using it was discarded. The new system proposed, called the Gonçalves-Monteiro system, is based on the changes presented by patients at the first consultation, establishing an increasing descriptive numerical scale (with an increase in the score reflecting the clinical evolution) to evaluate variables of walking, urinary and fecal incontinence, state of consciousness, seizures, and myoclonus/fasciculation.

The numerical evolution of the walking variable in the treated animals suggests that the infused cells probably modulated the inflammatory processes occurring in the myelin sheath, since attenuation of the clinical profile was observed. This inference is based on an association of information reported by Frisk et al. (1999) and Uccelli et al. (2011). While Frisk et al. (1999) were focused on showing that in dogs with inflammatory neurological injuries secondary to the distemper virus there was a high release of inflammatory cytokines, such as interleukin -10 and -6 , tumor necrosis factor, and transforming growth factor beta, Uccelli et al. (2011) demonstrated the immunomodulation exerted by the MSCs on the inflamed CNS. They described the induction of tolerance of peripheral $\mathrm{T}$ cells to 
myelin proteins that reduced the migration of pathogenic $\mathrm{T}$ cells to the CNS by preserving the axons and by means of the release of neurotrophins (such as the neurotrophic factor derived from the brain) and anti-inflammatory cytokines capable of modulating the local microenvironment and activating endogenous progenitors. In addition, some studies have shown that mononuclear bone marrow cells injected intraarterially and intravenously migrate to the CNS, generating a neuroprotection effect following transient focal cerebral ischemia in rats (Kamiya et al., 2008; Kamiya et al., 2014) and in dogs, with evidence of the migration of labeled cells to the site of the lesion (Chung et al., 2009).

Despite the attenuation of the observed clinical signs, the variables "Walking", "Urinary Incontinence", and "Fecal Incontinence" were the only ones that exhibited significant differences, emphasizing the relevance of treatment to reestablish minimum psychomotor functions and patient independence. As the neurological signs resulting from polyradiculoneuritis secondary to distemper were subtle, it is necessary to reassess this condition in canine patients using electroneuromyography to mitigate possible doubts that exist concerning variations in their intensity and partial remission.

We observed a decrease in frequency and duration of seizures over the 180-day evaluation period. Convulsive activities are mostly a consequence of demyelization (Martella et al., 2008), of the formation of oxygen free radicals by microglia that alter synaptic transmission and directly destroy neurons, of the excessive release of glutamate (an excitatory neurotransmitter) followed by its binding to its receptor (Stein et al., 2016) and by self-regulation of glutamate transporter expression (D'intino et al., 2006). Probably, therapy with MSCs affects paracrine activities associated with their capacity for fusion in neural cells, the functional recruitment of intact neurons and glial cells, generating angiogenesis stimulating mechanisms, regulating the uptake of glutamate and increasing the production of more extracellular matrix molecules that stimulate growth and axonal extension (D'intino et al., 2006; Colpo et al., 2015).

All MSC action in the organism is triggered by molecular interactions that these undifferentiated cells have with the receptor niche; in many situations, it becomes necessary for immunological stimuli by the stem cells to be immunosuppressive for the resolution of certain conditions (Uccelli et al., 2011; Abreu-Junior et al., 2014; Colpo et al, 2015). In light of this knowledge, we opted for therapy in patients with chronic signs and not in dogs that manifested clinical signs characteristic of the acute phase of distemper. It is known that, in the acute phase. the high rate of virus replication in the lymphoid tissues of dogs leads to lymphopenia from transient depletion of CD21+ B, CD8+ T, and CD4+ T cells (Carvalho et al, 2012), profound immunosuppression due to leukocyte necrosis and apoptosis (Carvalho et al., 2012; Beineke et al., 2015), and inhibition of the responses of interferon and cytokines secreted by the lymphoid cells (Greene and Vandevelde, 2012) and that, therefore, this immunodepression could be potentiated by exogenous use of MSC. This information may explain the success of the treatment that we applied when confronted with the data of Pinheiro et al. (2016) who observed a high mortality rate (67\%) among their patients; they used dogs that already presented severe respiratory and gastric clinical signs, in addition to neurological manifestations typical of the acute phase of distemper. 


\section{CONCLUSIONS}

An allogenic infusion of mesenchymal stem cells derived from adipose tissue, administered at a dose of $5.0 \times 10^{6}$ cells $/ 3.0 \mathrm{~mL}$ of PBS, in three applications 15 days apart to dogs with neurological sequelae from distemper was shown to be efficient and could be considered a treatment option in cases of chronic distemper. The benefits of this therapy became apparent starting at 15 days and were maintained over the 180 days of clinical evaluation.

\section{CONFLICTS OF INTEREST}

The authors declare no conflict of interest.

\section{REFERENCES}

Abreu-Junior NB,Del Carlo RJ, Favarato LSC, Favarato ES, et al.(2014). Mesenchymal Stem Cells in the treatment of Cerebral Ischemic Injury. Global J. Animal Sci. Res. 2: 83-91.

Beineke A, Baumgärtner W, Wohlsein P (2015). Cross-species transmission of canine distemper virus- an update. One Health. 1: 49-59.

Beineken A, Puff C, Seehusen F, Baumgärtner W (2009). Pathogenesis and immunopathology of systemic and nervous canine distemper. Vet Immunol Immunopathol. 127: 1-18.

Carvalho OV, Botelho CV, Ferreira CGT, Scherer PO, et al. (2012). Immunopathogenic and neurological mechanisms of canine distemper virus. Adv Virol. 2012: 163860.

Chung DJ, Choi BC, Lee SH, Kang EH et al. (2009). Intraarterially delivered human umbilical cord blood-derived mesenchymal stem cells in canine cerebral ischemia. J Neurosci Res. 87: 3554-3567.

ColpoGD, Ascoli BM, Wollenhaupt-Aguiar B, Pfaffenseller B, et al. (2015). Mesenchymalstem cellsfor the treatment of neurodegenerative and psychiatric disorders. An Acad Bras Cienc. 87: 1435-49.

D'intinoG, Vaccari F, Sivilia S, Ecagliarini A, et al. (2006). A molecular study of hippocampus in dogs with convulsion during canine distemper virus encephalitis. Brain Res. 1098: 186-195.

Fischer UM, Harting MT, Jimenez F, Monzon-Posadas WO, et al. (2009). Pulmonary passage is a major obstacle for intravenous stem cell delivery: the pulmonary first-pass effect. StemCells Dev. 18: 683-692.

Frisk AL, Baumgärtner W, Gröne A. (1999). Dominating interleukin-10 mRNA expression induction in cerebrospinal fluid cells of dogs with natural canine distemper induced demyelinating and non-demyelinating CNS lesions. J Neuroimmunol. 97: 102-109.

Greene CE and Vandevelde M.(2012). Infectious Disease of the Dog and Cat. In: Canine distemper. Greene CE and Vandevelde M. editors, 4 ed, Editora Elsevier, Georgia, pp. 25-41.

Kamiya F, Masayuki U, Nito C, Kaiya N, et al. (2014). Effect of repeated allogeneic bone marrow mononuclear cell transplantation on brain injury following transient focal cerebral ischemia in rats. Life Sci. 95: 22-28.

Kamiya N, Ueda M, Igarashi H, Nishiyama Y, et al. (2008). Intra-arterial transplantation of bone marrow mononuclear cells immediately after reperfusion decreases brain injury after focal ischemia in rats. Life Sci. 83: 433-437.

Kanamaru T, KamimuraN, Yokota T, Nishimaki K, et al. (2015). Intravenous transplantation of bone marrow-derived mononuclear cells prevents memory impairment in transgenic mouse models of Alzheimer's disease. Brain Res. 1605: 49-58.

Marques AR (2016). Terapia com células estaminais em cães com sequelas neurológicas da esgana. Master's thesis, Universidade Lusófona de Humanidades e Tecnologias, Lisboa.

Martella V, Elia, G, Bounavoglia C (2008). Canine Distemper Virus. Vet Clin Small Anim. 38: 787-797.

Meirelles LS, Caplan AI, Nardi BN (2008). In search of the in vivo identity of Mesenchymal Stem Cells. Stem Cells. 26: 2287-2299.

Moazzami K, Moazzami B, Roohi A, Nedjat S, et al. (2014). Local intramuscular transplantation of autologous mononuclear cells for critical lower limb ischaemia. Cochrane Database Syst Rev. 19:CD008347.

Monteiro BA (2017). Efeitos da terapia com células tronco mesenquimais em afecções do sistema nervoso de cães. Doctoral thesis, Universidade Estadual Paulista, Botucatu.

Monteiro BS, Favarato L, Carvalho P, Okano B, et al. (2015). Clinical and radiographic characterization of xenotransplantation of rat boné marrow-derived mesenchymal stem cells for repair of radial defects of rabbit. Turk J Vet Anim Sci. 39:511-519. 
Olby NJ, De Risio L, Muñana KR, Wosar MA, et al. (2001). Development of a functional scoring system in dogs with acute spinal cord injuries. Am J Vet Res.62: 1624-1628.

Oliveira APL, Rangel JPP, Raposo V, Pianca NG, et al. (2018). Allogenic mesenchymal stem cells intravenous infusion in reparation of mild intestinal ischemia/reperfusion injury in New Zealand rabbits. Pesq. Vet. Bras. 38:710-721.

Pinheiro AO, Cardoso MT, Vidane AS, Casals JB, et al. (2016). Controversial results of therapy with mesenchymal stem cells in the acute phase of canine distemper disease. Genet Mol Res. 15: gmr8310.

Pinto Filho STL, Treichel TLE, Aramburú Junior JS, Da Rosa MB, et al. (2013). Células-tronco mesenquimais adultas: características e aplicações experimentais em animais. Vet. Zootec. 20: 49-59.

Seehusen F, Al-Azreg AS, Raddatz BB, Haist V, et al. (2016). Accumulation of extracellular matrix in advanced lesions of canine distemper demyelinating encephalitis. PLoS One. 11(7):e0159752.

Stein VM, Baumgärtner W, Kreienbrock L, Zurbriggen A, et al. (2006). Canine microglial cells: Stereotypy in immunophenotype and specificity in function?. Vet Immunol Immunopathol. 113: 277-287.

Takenaka A, Sato H, Ikeda F, Yoneda M, et al. (2016). Infectious Progression of Canine Distemper Virus from Circulating Cerebrospinal Fluid into the Central Nervous System. J Virol. 90: 9285-9292.

Uccelli A, Benvenuto F, Laroni A, Giunti D (2011). Neuroprotective features of mesenchymal stem 